\title{
DO WE NEED TO FORGET FIXATIONS TO INCUBATE? A PARADOX OF THE FORGETTING FIXATION THEORY
}

\author{
E.A. VALUEVA ${ }^{a}$, N.M. LAPTEVA ${ }^{a}$ \\ ${ }^{a}$ Institute of Psychology, Russian Academy of Sciences, 13 build. 1, Yaroslavskaya Str., Moscow, 129366, \\ Russian Federation
}

\begin{abstract}
The incubation period is regarded as an important stage in creative problem solving. The incubation effect manifests itself in the enhanced problem-solving performance after taking a break. Forgetting fixation hypothesis states that incubation provides a problem solver with an opportunity to eliminate inappropriate ideas (mental sets) and therefore to come up with a correct solution. We explored in two studies whether forgetting is an actual mechanism of the incubation period (i.e. whether the traces of inappropriate fixations in memory become weaker as a consequence of incubation). In Study 1 we employed the Alternative Uses Task (AUT) and fixed part of the participants on several most common ways of using an object. We checked then whether incubation helped to forget our fixations. We found the incubation effect (i.e. a greater fluency at the second attempt) only when participants were previously fixated. However, we also found that the incubation didn't influence the number of fixations. Thus, we failed to find the evidence for forgetting fixation during the incubation period. In Study 2 we used anagrams with two possible solutions and fixed the participant on one of them. Then we used the Lexical Decision Task (LDT) to examine whether these fixations would become weaker as a result of the incubation period. No differences were found between the incubation and no-incubation groups in their response latencies for fixation words. Our results indicate that while the assumption that the function of an incubation period is in overcoming inappropriate mental sets seems to be true, the forgetting fixation theory provides an inaccurate account of underlying mechanisms.
\end{abstract}

Keywords: incubation, fixation, forgetting fixation hypothesis, Alternative Uses Task, anagrams, Lexical Decision Task.

The incubation period is regarded as an important stage in creative problem solving (Wallas, 1926). The incubation effect manifests itself in the enhanced problem-solving performance after taking a break. Although experimental data on the existence of the incubation effect is somewhat inconsistent, meta-analytic reviews show a positive incubation effect (though it could vary across different problem types and other moderator variables) (Sio \& Ormerod, 2009; Strick, Dijksterhuis, Bos, \& Nordgren, 2011).

Several theories exist explaining underlying cognitive mechanisms of successful incubation (Lapteva, 2020; Smith, 2011). One of them, the forgetting fixation hypothesis (Smith, 1995), states that incubation provides a problem solver with an opportunity to eliminate inappropriate ideas (mental sets) and therefore to come up with a correct solution. This theory seems rather plausible (at least, for linguistic problems (Sio \& Ormerod,

This work was supported by the Russian Science Foundation 17-78-30035. 
2009) since many studies could achieve an incubation effect only if they employ some kind of fixation or misleading cues on the initial stage of problem solving (Kohn \& Smith, 2009; Penaloza \& Calvillo, 2012; Smith \& Blankenship, 1991; Valueva, 2016; Vul \& Pashler, 2007). But could we consider the title of this theory (i.e. "forgetting") as an actual mechanism of the incubation period? Do inappropriate fixations indeed become forgotten (i.e. their traces in memory become weaker) as a consequence of incubation? This assumption has never been thoroughly tested. Some evidence for real forgetting could be found in Koppel and Storm (Koppel \& Storm, 2013). They found that retrieval-induced forgetting (the measure of the ability to inhibit inappropriate responses) correlated with problem solving performance in the no-incubation group, but didn't correlate with problem solving performance in the incubation group after the incubation period. It could be that incubation minimizes the need for inhibition by weakening fixation traces in memory. Therefore, the ability to inhibit fixation becomes irrelevant.

Sio and Rudowicz (Sio \& Rudowicz, 2007) and Sio (Sio, 2010) took lexical decision times as a measure of the misleading element's activation. Sio and Ridowicz used three types of remote association tasks (RAT) - neutral, GO-relevant ${ }^{1}$, and GO-misleading - and tested experts in GO and GO novices. GO-misleading RATs were supposed to evoke fixation in GO experts. After an initial attempt to solve the RAT participants performed the LDT either immediately (no incubation) or after an incubation period. Each RAT was followed by a LDT series, which incorporated the RAT solution, an irrelevant (misleading) concept and neutral words. As expected, experts solved less GO-misleading items. Contrary to expectation, the experts' reaction times for misleading words were faster under the incubation condition (compared to the reaction times of experts under no incubation condition). This means that forgetting of irrelevant concepts does not occur. Another explanation, however, is possible. The descriptive statistics provided in Sio's Table 2 shows that experts' RTs in incubation condition are systematically faster than in other conditions. Unfortunately, for unknown reasons, Table 3 with MANOVA results is missing from the paper, that is why we can't check for the significance of these differences. So, results seem inconclusive.

Sio (Sio, 2010, Experiment III) used neutral and misleading Rebuses and found no differences in lexical decision times for neutral words and misleading hints either in the incubation or in the no-incubation conditions. This could clearly indicate the lack of support for forgetting fixation, if it was not for the fact that Sio failed to find any incubation effect in general. Thus, again we can't be sure whether the incubation period leads to fixation forgetting.

In order to investigate this question more explicitly, we conducted two studies. In Study 1 we employed the Alternative Uses Task (AUT) and fixed part of the participants on several most common ways of using an object. We checked then whether incubation helped to forget our fixations. In Study 2 we used anagrams with two possible solutions and fixed the participant on one of them. Then we examined whether these fixations would become weaker as a result of the incubation period.

\section{Study 1}

Study 1 investigated whether an incubation period enhances productivity in a divergent thinking task by producing fixation forgetting. The Alternative Uses Task (AUT)

\footnotetext{
${ }^{1} \mathrm{GO}$ is an ancient Chinise board game.
} 
(Guilford, Christensen, Merrifield, \& Wilson, 1978) is a commonly used measure of divergent thinking where a participant is asked to think of as many uses for a well-known object (such as a newspaper) as possible. The difficulty of this task lies in overcoming obvious and recently encountered uses for an object. In order to ensure fixation Storm and Patel had participants study several common uses before asking them to generate new uses of an object (Storm \& Patel, 2014). We applied a similar, but a less straightforward procedure. Before the AUT we exposed participants to several pictures (which represented the most common uses of an object) and asked them to title these pictures. According to forgetting fixation account, we were supposed to find: 1) a greater fluency and 2) fewer fixations (i.e. answers that correspond to pictures) due to an incubation period.

\section{Method}

\section{Participants}

Two hundred ninety females and 102 males participated in the experiment for payment. The average age was $30.62(\mathrm{SD}=11.67)$. They were enrolled via advertisements on social networks (VKontakte, Facebook, etc.). A detailed sample description by experimental conditions is presented in Table 1.

\section{Materials}

Alternative Uses Task. In our adapted version of AUT, we used only one object as a stimulus (a match).

Pictures. In our previous study (unpublished data) more than 300 participants generated ideas on how to use a matchstick. We calculated frequencies of produced ideas and revealed the five most prevalent categories (to kindle a fire, to build little houses, to draw with the burnt end of a match, to use as a toothpick, to use as a cotton bud). We selected five appropriate pictures (fixating pictures) which were intended to represent these categories. Three pictures unconnected with match problem served as fillers.

Either Raven's Advanced progressive matrices (APM) or Revised Purdue Spatial Visualization Test (PSVT:R) were used as an incubation task. We used a short form of the APM consisting of 12 items (Bors \& Stokes, 1998). PSVT:R (shortened version, only even items of the original test were used) consisting of 15 items intended to measure the 3D mental rotation ability (Yoon, 2011a, 2011b) ${ }^{2}$. Each test took approximately the same time to accomplish ( $\mathrm{M}=7.9 \mathrm{~min}$ and $\mathrm{M}=6.8 \mathrm{~min}$, respectively), and both could be classified as high cognitive load tasks (Sio \& Ormerod, 2009).

\section{Procedure}

All data was collected on-line and was divided into two phases. During the first phase we collected data for the fixation group, during the second one, for the group without fixations.

In the fixation group, the procedure was implemented by using the software PsyToolkit (Stoet, 2010, 2017). Each participant was randomly assigned either to the

\footnotetext{
${ }^{2}$ We are greateful to Dr. So Yoon Yoon for providing us with the PSVT:R and appreciate her valuable suggestions on using it.
} 
incubation or to the no-incubation group. First of all, participants were asked to give humoristic titles to eight pictures (three neutral and five fixating ones). They then proceeded to the AUT task. Participants were instructed to think of as many unusual uses of a match as possible. They were encouraged to generate innovative and creative ideas. In the no-incubation group, participants were told that they had to generate ideas for 3 minutes (first attempt) and afterwards they would immediately be given another 2 minutes to continue (second attempt). In the incubation group, participants were informed that they had to generate ideas for 3 minutes (first attempt), then they would be given a break and would solve another task (APM or PSVT:R), and then they would return to AUT for another 2 minutes (second attempt).

In the no-fixation group, the procedure was implemented using the software developed by A. Panfilova for the purpose of this project. The procedure and the presentation of the tasks were identical except that the picture-naming task was eliminated.

\section{Results}

Background statistics. For each participant, we calculated fluency scores (i.e. the number of sensible ideas proposed) for the first (fluency 1) and second (fluency 2) attempts. To determine the number of fixations, an expert (blind to the participants' belonging to any experimental conditions) identified correspondence between a participant's answers and fixating pictures. We calculated the number of fixations identified and for each attempt calculated the proportion of fixations (a fixation score) relative to overall fluency on the corresponding attempt. All descriptive statistics are presented in Table 1.

It was revealed that the fixation group turned out to be significantly younger than nofixation group $(t(390)=-7.25, p<.001)$. However, as age didn't correlate significantly with any of the fluency or fixation scores ( $r$ ranged from -.06 to 0.03 , ns) we assumed that it wouldn't be a confounding factor. It was also revealed that the baseline fluency score (fluency 1) significantly differed in the fixation $(\mathrm{M}=5.84)$ and no-fixation $(\mathrm{M}=4.82)$ groups $(t(390)=3.4, p=.001)$. Therefore, all comparisons involving these groups were made controlling for baseline fluency. All other between-group comparisons involving age and fluency 1 were not statistically significant.

Incubation effect. To check up on the presence of the incubation effect a 2 (fixation) $\times 2$ (incubation) ANCOVA (with fluency 1 as a covariate) were carried out using the fluency 2 as dependent variable (DV). We found a significant main effect of incubation $(F(1,387)=6.95$, $\left.p=.009, \eta^{2}=.02\right)$ and significant interaction between incubation and fixation conditions $\left(\mathrm{F}(1,387)=5.03, \mathrm{p}=.025, \eta^{2}=.01\right.$, see Figure 1$)$. Subsequent analysis revealed a significant main effect of incubation in the fixation group $\left(F(1,127)=8.87, p=.003, \eta^{2}=.06\right)$, but insignificant results in the no-fixation group $\left(F(1,259)=0.15, p=.703, \eta^{2}=.001\right)$. These results are in accordance with the forgetting fixation theory since the incubation effect was found only in the participants who were previously fixated.

Fixation effect. We then examined the effects of the fixation task on the participants' performance searching for differences in fixation scores between the groups. There were no significant differences between fixation and no-fixation groups in the fixation score at the first attempt $(\mathrm{t}(390)=-0.94, p=.350)$. This result suggests that there was no immediate fixation effect. 
Table 1

Number of Participants, Means (Standard Deviations) of Age, Fluency and Fixations by Conditions

\begin{tabular}{|l|c|c|c|c|c|c|c|}
\hline \multirow{2}{*}{} & N & Age & \multicolumn{2}{c|}{ First attempt } & \multicolumn{2}{c|}{ Second attempt } \\
\cline { 3 - 8 } & & & Fluency 1 & $\begin{array}{c}\text { Fixation } \\
\text { score 1 }\end{array}$ & Fluency 2 & $\begin{array}{c}\text { Fixation } \\
\text { score 2 }\end{array}$ \\
\hline \multicolumn{7}{|c|}{ Fixation group } \\
\hline Incubation & 71 & $24.32(7.11)$ & $6.00(2.52)$ & $.33(.23)$ & $3.94(2.29)$ & $.18(.24)$ \\
\hline No-incubation & 59 & $25.63(11.83)$ & $5.64(2.77)$ & $.35(.24)$ & $2.90(1.72)$ & $.13(.22)$ \\
\hline \multicolumn{7}{|c|}{ No-fixation group } \\
\hline Incubation & 135 & $34.47(11.74)$ & $4.99(3.13)$ & $.36(.26)$ & $3.12(2.16)$ & $.25(.29)$ \\
\hline No-incubation & 127 & $32.35(11.42)$ & $4.64(2.35)$ & $.36(.25)$ & $2.91(1.85)$ & $.21(.28)$ \\
\hline \multicolumn{7}{|c|}{ Overall } \\
\hline Fixation group & 130 & $24.92(9.53)$ & $5.84(2.63)$ & $.34(.23)$ & $3.47(2.11)$ & $.16(.23)$ \\
\hline No-fixation group & 262 & $33.45(11.61)$ & $4.82(2.78)$ & $.36(.26)$ & $3.02(2.02)$ & $.23(.29)$ \\
\hline Incubation & 206 & $30.98(11.44)$ & $5.34(2.96)$ & $.35(.25)$ & $3.4(2.23)$ & $.23(.28)$ \\
\hline No-incubation & 186 & $30.22(11.94)$ & $4.96(2.53)$ & $.36(.24)$ & $2.9(1.8)$ & $.19(.26)$ \\
\hline
\end{tabular}

Figure 1

ANCOVA Results for the Incubation Effect in Study 1 (Error bars represent 95\% CI)

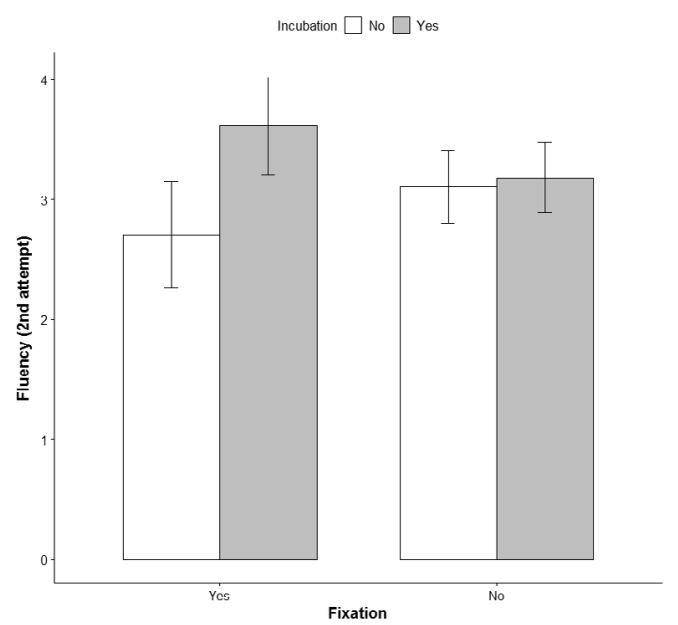

A 2 (fixation) $\times 2$ (incubation) ANCOVA (with fluency 1 as a covariate) were carried out using the fixation score 2 as DV (see Figure 2). The main effect of incubation was not significant $\left(F(1,379)=3.10, p=.079, \eta^{2}=.008\right)$, nor was the interaction between fixation and incubation $\left(F(1,379)=0.01, p=.922, \eta^{2}=.000\right)$. We found, however, that fixation 
Figure 2

ANCOVA Results for the Fixation Effect in Study 1 (Error bars represent 95\% CI)

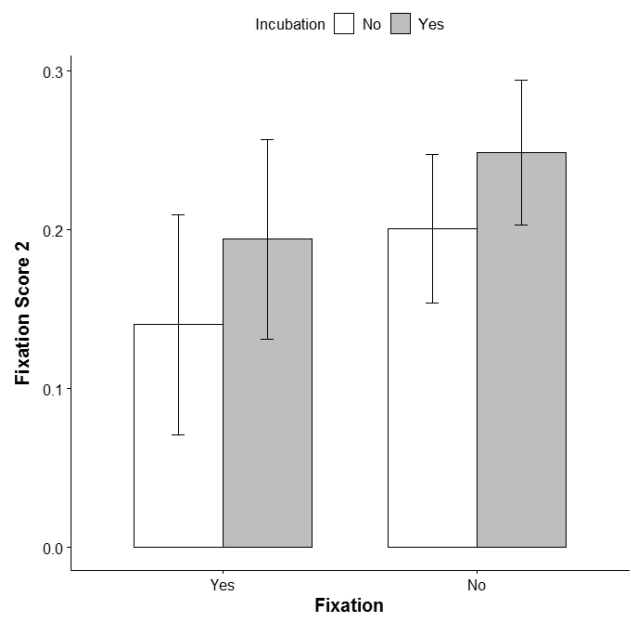

score 2 was higher in the no-fixation group, which was indicated by the significant fixation effect, $\left(F(1,379)=3.84, p=.051, \eta^{2}=.01\right)$.

Forgetting fixations effect. To verify whether incubation induces forgetting fixation we analyzed fixation score 2 in the fixation group. T-test revealed no significant differences between incubation and no-incubation groups $(\mathrm{t}(125)=-1.15, p=.252)$. It seems to show that no forgetting fixation occurred.

\section{Discussion}

Study 1 demonstrated the incubation effect as a function of fixating manipulation. We found greater fluency in the incubation group only when participants were previously fixated on the common uses of a match. Despite being in line with the forgetting fixation account, these results are rather surprising because divergent thinking problems are known to be the most liable to incubation (Sio \& Ormerod, 2009). So, we could expect to find successful incubation regardless of fixation conditions. In this experiment, we took only the fluency as a performance measure. Perhaps, considering other measures (i.g. originality, flexibility) would lead to different results in the no-fixation group.

We also found that our fixation task had no immediate effect (at the first attempt), but rather a delayed reversed one (manifesting itself in the second attempt). One possible explanation could be that all participants had already been fixated on the most common uses of the ordinary object by their past experience. Therefore, some kind of a ceiling effect probably was observed in both groups at the first attempt (both groups produced as many fixations as possible). At the second attempt, the no-fixation group managed to dispose of artificially reinforced fixations, but the fixation group was still stuck on natural fixations.

We failed to find the evidence for forgetting fixationduring the incubation period. It seems that (at least in divergent thinking tasks) the incubation period helps to overcome adherence to inappropriate ideas, but the underlying mechanism is not that of forgetting. 


\section{Study 2}

In Study 2 we used a linguistic task (anagrams with two possible answers), fixated participants by priming one of the solutions, and examined whether these fixations would become weaker after the incubation period.

In our previous research that employed anagrams with two possible solutions, we found that the incubation effect occurred only if participants were fixated on one of the solutions (Valueva, 2016). To fixate participants, we firstly presented anagrams along with one solution (a primed solution). The second solution (an alternative) was hindered (Lapteva, Valueva, \& Belova, 2018). After about a week, participants had to solve these anagrams either with an incubation or without an incubation period. The incubation effect was observed only in the case of alternative solutions; neither primed nor neutral solutions benefited from the incubation period.

In the present study, we investigated whether the observed incubation effect would be accompanied by the weakening of fixation traces. We employed the same procedure along with the Lexical Decision Task (LDT). The LDT served as a measure to assess the participants' sensitivity to different memory items. According to forgetting fixation account, sensitivity to fixation elements (primed solutions) would weaken as a result of the incubation period. This would lead to increased lexical latencies in the incubation group compared to the no-incubation group.

\section{Method}

\section{Participants}

Thirty-four females and 18 males participated in the experiment. They were volunteers who responded to advertisements in social networks (VKontakte, Facebook, etc.). The average age was 26.69 ( $\mathrm{SD}=7.29)$. All participants were randomly assigned to the incubation $(\mathrm{N}=27)$ or no-incubation $(\mathrm{N}=25)$ conditions.

\section{Materials}

Anagrams. The 36 five to seven-letter anagrams with two possible solutions were selected (see Figure 3 for examples). Each of the 72 solutions was a singular noun. Anagrams were divided into two sets of 18 (Set A and Set B).

LDT. A set of LDTs consisted of 72 anagram solutions and 72 pseudowords. Each pseudoword was composed by random substitution of one letter in a word (noun). Vowels were replaced by vowels (for example, "villain" to "sillain"); consonants were replaced by consonants (for example "beauty" to "biauty"). There were no direct semantic associations between pseudowords and anagram solutions.

All verbal stimuli were in Russian.

Raven's Advanced Progressive Matrices (APM) were used as an incubation task (the short form, Bors \& Stokes, 1998).

\section{Procedure}

All tasks were implemented in E-Prime 2.0 (Schneider, Eschman, \& Zuccolotto, 2012). The experiment was conducted in two days with approximately a seven day gap between them. 
On the first day, participants were shown pairs of anagrams and one possible solution to this anagram. Pairs were presented in a random order in the centre of the screen: an anagram appeared first and after $3 \mathrm{sec}$ it was joined by its solution. The pair remained on the screen until $5 \mathrm{sec}$ elapsed. Participants were asked just to watch stimulus material and take no actions. They were told that it was needed to become acquainted with the anagram task and were not told that anagrams had alternative solutions. All participants were randomly divided into four groups. Each group saw only 18 anagrams (either Set A or Set B) and only one solution per anagram (see Figure 3 for illustration). This procedure was assumed to induce fixation on one of the two solutions.

On the second day, all participants solved 36 anagrams (Set A + Set B). Half of the participants were told that after the first attempt they would immediately be given a second chance to find solutions for unsolved anagrams (no-incubation group). Half of the participants were informed that after the first attempt they would shift to another task and then return to the unsolved anagrams (incubation group). Anagrams were presented one by one in random order in the centre of the screen for $15 \mathrm{sec}$ or until the problem was solved. When participants arrived at the solution, they had to press the «space» key and type their solution into a text box. Before proceeding to the main task the participants solved four anagrams to practice.

After the first attempt, the no-incubation group proceeded immediately to the LDT. The incubation group performed an incubation task (Raven's APM) and then switched to the LDT. After the LDT participants had the second attempt to solve unsolved items, but this data was not analyzed as during the LDT participants encountered anagram solutions which could be confounding.

In LDT 144 stimuli (72 words and 72 pseudowords) were sequentially presented in the centre of the screen in a random order. Before each stimulus, a fixation cross appeared on the screen for $0.5 \mathrm{sec}$ to draw the participants' attention. Participants were prompted to press the 1 key as quickly and accurately as possible if the item presented was a word, or the 0 key if it was a pseudoword. The stimulus remained on the screen until an answer had been given. Before the main task participants solved six practice items.

\section{Results}

Anagram solving. All participants' solutions were classified into three categories (see Figure 3):

Figure 3

Experimental Design of Study 2

\begin{tabular}{|c|c|c|c|c|c|c|}
\hline & & & & & & \\
\hline & & & GROUP 1 & GROUP 2 & GROUP 3 & GROUP 4 \\
\hline & \multirow{2}{*}{$\begin{array}{c}\text { Set A } \\
18 \text { anagrams } \\
\text { e. g. «netuim» }\end{array}$} & Answer 1 & primed & alternative & neutral & neutral \\
\hline & & Answer 2 & alternative & primed & neutral & neutral \\
\hline \multirow[t]{3}{*}{$\begin{array}{c}36 \\
\text { anagrams }\end{array}$} & & & & & & \\
\hline & \multirow{2}{*}{$\begin{array}{c}\text { Set B } \\
18 \text { anagrams } \\
\text { e. g. "gitnh" }\end{array}$} & $\begin{array}{l}\text { Answer } 1 \\
\text { «thing" }\end{array}$ & neutral & neutral & primed & alternative \\
\hline & & $\begin{array}{c}\text { Answer } 2 \\
\text { «night» }\end{array}$ & neutral & neutral & alternative & primed \\
\hline
\end{tabular}


1. Primed solutions were those which had been presented to participant on the first day.

2. Alternative solutions were the second (not presented solutions) for the anagrams presented on the first day.

3. Neutral solutions corresponded to anagrams which were not presented to the participant on the first day.

For each participant, we calculated the mean proportion of correct solutions in each category (at the first attempt, before the LDT). As expected, we found that the proportion of primed solutions was higher $(\mathrm{M}=.32, \mathrm{SD}=.13)$ than the proportion of either alternative $(\mathrm{M}=.17, \mathrm{SD}=.10, \mathrm{t}(50)=7.12, \mathrm{p}<.001)$ or neutral $(\mathrm{M}=.19, \mathrm{SD}=.10, t(50)=7.99$, $p<.001)$ solutions. The proportions of alternative and neutral solutions were also significantly different $(t(50)=-2.00, p=.05)$. These results are perfectly the same as in our previous study (Valueva, 2016). We assume that a correspondence between two experiments could be established.

LDT. Before the analysis, we excluded response latencies of less than $200 \mathrm{~ms}$ and more than 2SD from the overall average that was less than $1.5 \%$ of all responses. Incorrect lexical decisions and lexical decisions for words corresponding to the solved anagrams were also discarded. After that, the means of the lexical latencies for different categories of solutions (i.e. primed, alternative, neutral and pseudowords) were calculated.

Mean response latencies for pseudowords didn't differ significantly in the incubation $(\mathrm{M}=975.0 \mathrm{~ms}, \mathrm{SD}=249.7 \mathrm{~ms})$ and no-incubation $(\mathrm{M}=938.4 \mathrm{~ms}, \mathrm{SD}=273.7 \mathrm{~ms})$ groups $(t(50)=-0.50, p=.62)$. This ensures that any difference found (or not found) in the subsequent analysis could not be attributed to differences in the general speed.

If a forgetting fixation occurs during an incubation period, we were supposed to find our subjects less sensitive to primed solutions (i.e. to fixations) after the incubation. In other words, response latencies to primed solutions should be slower in the incubation group compared to the no-incubation group.

To test this prediction a 3 (Category of Solution) $\times 2$ (Incubation) ANOVA were carried out with repeated-measures on Category of Solution (primed, alternative, neutral) and LDT response latencies as DV (see Figure 4). The significant main effect of the Category of Solution $\left(F(2,49)=8.303, p<.001, \eta^{2}=.14\right)$ indicated that the response latencies for primed $(\mathrm{M}=807.0 \mathrm{~ms}, \mathrm{SD}=181.1 \mathrm{~ms})$ solutions were significantly quicker than for alternative $(\mathrm{M}=864.1 \mathrm{~ms}, \mathrm{SD}=223.7 \mathrm{~ms}, t(51)=-3.38, p=.001)$ and for neutral solutions $(\mathrm{M}=872.1 \mathrm{~ms}, \mathrm{SD}=190.3 \mathrm{~ms}, t(51)=-3.80, p<.001)$. Alternative and neutral solutions didn't differ significantly $(t(51)=-0.45, p=.652)$. Neither main effect of Incubation $\left(\mathrm{F}(2,50)=0.06, p=.805, \eta^{2}=.001\right)$, nor the interaction effects $(F(2,49)=0.84$, $\left.p=.433, \eta^{2}=.017\right)$ were significant. No differences were found between incubation and no-incubation groups' in response latencies for any category of solutions (all $p s>.600$ ).

\section{Discussion}

Study 2 revealed that on the cognitive level (memories activation) no forgetting fixation occurs during an incubation period. Combined with our previous study on the same stimulus material (Valueva, 2016), this suggests that although incubation enhances anagram solving only in a fixation condition, forgetting fixation doesn't seem to be a cognitive mechanism of incubation effect. 
ANOVA Results for LDT (Error bars represent 95\% CI)

Figure 4

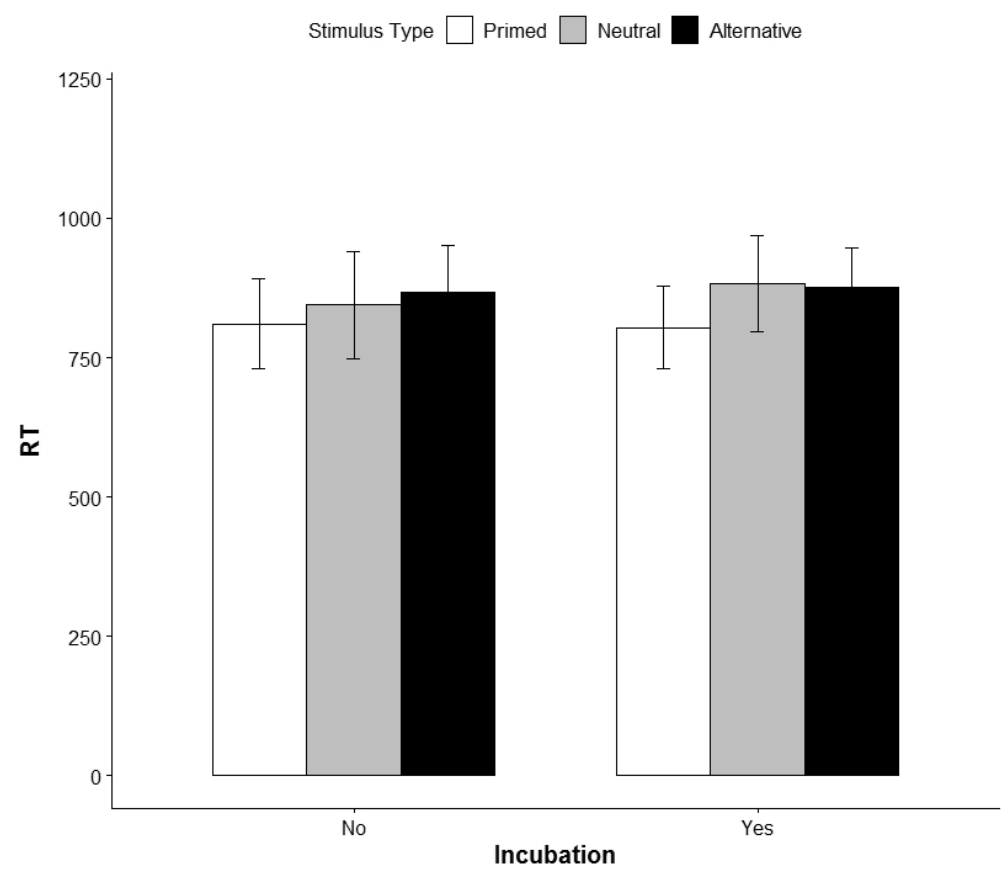

Our data allows us to check upon another influential theory of incubation, i.e. spreading activation hypothesis. Spreading activation hypothesis implies that the incubation period allows activation from problem elements spread via a semantic network to the relevant memories. If spreading activation serves as the source of incubation effect, then response latencies in the LDT for unsolved anagrams' solutions should decrease over the incubation period. We found no empirical support for this assumption: there were no significant differences in the LDT performance between the incubation and no-incubation groups. Thus, we are forced to conclude that although the incubation effect took place, neither forgetting fixation nor spreading activation occurred.

\section{General Discussion}

We conducted two studies using different types of problems (a divergent thinking task and linguistic problems). In both experiments, we failed to find the evidence for fixation forgetting as a cognitive mechanism of an incubation period. Nevertheless, in both cases, an incubation effect was observed whenever fixations were present. While the assumption that the function of an incubation period is in overcoming inappropriate mental sets seems to be true, forgetting fixation theory provides an inaccurate account of underlying mechanisms.

If fixation forgetting doesn't work, several possible candidates for explanatory mechanisms could be mentioned. 
E. Segal proposed the returning-act hypothesis according to which an incubation period merely diverts the attention of a solver from a problem and gives him or her an opportunity of a "fresh start" after a break (Segal, 2004). But it is still unclear why the solver should adopt a "fresh look" after an incubation period rather than to return to his unimpaired fixations.

Smith and Beda (Smith \& Beda, 2020) suggest the context-dependent fixation hypothesis. It assumes that fixations can become associated with the initial problem-solving context. When the context is reinstated fixations continue to block solutions. The environmental context includes any cues (photos, words, sounds etc.) associated with the initial attempt of problem solving. The temporal context is characterized as a period encompassing a set of events. Under this account, incubation provides relief from the temporal context, but as shown in Smith and Beda (Smith \& Beda, 2020) the effect could be reinforced by establishing new environmental context at the same time.

Other interpretation comes from V.M. Allakhverdov's theory of unconscious negative choice (Allakhverdov, 2006). According to Allakhverdov negative choice is an unconscious decision to inhibit certain information in favour of other information. If one is fixated on inappropriate information, solution relevant information would be negatively chosen. It was experimentally shown that negatively chosen information and absent information are not equivalent and that negatively chosen information tends to remain inhibited when appealed in the same problem solving context (Allakhverdov, 1993). For example, people often repeat their slips of the tongue, slips of the pen, misprints and other mistakes in cognitive or motor actions (Andriyanova, \& Allakhverdov, 2020, Gershkovich et al., 2013). A negative choice is problem-dependent, that is why we need to change the task to withdraw a "flag" of negative choice. It could be enough to turn your copy-book upsidedown to check the work more effectively. Incubation could be regarded as a way to change the subjective perception of a problem in order to cancel existent negative choices.

Ya. A. Ponomarev's theory of intuitive and logical modes of thinking also give us some clues to understand the mechanisms of an incubation period (Ponomarev, 1960). Information in the intuitive (subconscious, automatic) level appears as by-products of our action at a logical (conscious, deliberate, explicit) level. When a task is initially tackled some useful knowledge could be activated at the intuitive level as a by-product of our conscious efforts to solve a problem. However, a solver could not easily become aware of the relationships between a problem and this intuitive knowledge (Zhong, Dijksterhuis, \& Galinsky, 2008). The function of an incubation period is then, to provide our unconscious the time to establish these necessary links. Once ties are established a problem could be solved.

In our study, we have shown what cognitive mechanisms of incubation are probably not, but further research is needed to reveal what they are. This understanding would give us valuable hints of how to properly use an incubation period in our everyday problem solving and how not to misuse it. 


\section{References}

Allakhverdov, V. M. (1993). Opyt teoreticheskoj psikhologii [The experience of theoretical psychology]. Saint Petersburg: Publishing House of St. Petersburg State University. (in Russian)

Allakhverdov, V. M. (2006). Osoznanie kak otkrytie [Awareness as a discovery]. In D. V. Ushakov (Ed.), Psikhologiya kreativnosti. Shkola Ya.A. Ponomareva [Psychology of creativity. Ya.A. Ponomarev's school]. Moscow: Institute of Psychology of the RAS. (in Russian)

Andriyanova, N. V., Allakhverdov, V. M. (2020). Why do we step on the same rake? The occurrence of recurring errors in the learning process. Psychology. Journal of Higher School of Economics, 17(4), 791-802.

Bors, D. A., \& Stokes, T. L. (1998). Raven's Advanced Progressive Matrices: Norms for first-year university students and the development of a short form. Educational and Psychological Measurement, 58(3), 382-398. doi:10.1177/0013164498058003002

Gershkovich, V. A., Moroshkina, N. V., Allakhverdov, V. M., Ivanchei, I. I., Morozov, M. I., Karpinskaya, V. Y., ... Volkov, D. N. (2013). Constant errors in sensor-motor learning and their correction. Vestnik Sankt-Peterburgskogo Universiteta. Series 16(3), 43-54. (in Russian)

Guilford, J. P., Christensen, P. R., Merrifield, P. R., \& Wilson, R. C. (1978). Alternate uses: Manual of instructions and interpretations. Orange, CA: Sheridan Psychological Services.

Kohn, N., \& Smith, S. M. (2009). Partly versus completely out of your mind: Effects of incubation and distraction on resolving fixation. The Journal of Creative Behavior, 43(2), 102-118. doi:10.1002/j.2162-6057.2009.tb01309.x

Koppel, R. H., \& Storm, B. C. (2013). Escaping mental fixation: Incubation and inhibition in creative problem solving. Memory, 22(4), 37-41. doi:10.1080/09658211.2013.789914

Lapteva, N. M. (2020). Incubation period in creative problem solving: Hypotheses and research prospects. Psychology. Journal of Higher School of Economics, 17(4), 630-644. (in Russian)

Lapteva, N. M., Valueva, E. A., \& Belova, S. S. (2018). Priming effects in a lexical decision task based on transposed-letter word pairs. Psychology. Journal of Higher School of Economics, 15(4), 747-757. (in Russian)

Penaloza, A., \& Calvillo, D. P. (2012). Incubation provides relief from artificial fixation in problem solving. Creativity Research Journal, 24(4), 338-344. doi:10.1080/10400419.2012.730329

Ponomarev, Y. A. (1960). Psikhologiya tvorcheskogo myshleniya [Psychology of creative thinking]. Moscow: Izdatel'stvo Akademii pedagogicheskikh nauk RSFSR. (in Russian)

Schneider, W., Eschman, A., \& Zuccolotto, A. (2012). E-Prime user's guide. Pittsburgh, PA: Psychology Software Tools, Inc.

Segal, E. (2004). Incubation in insight problem solving. Creativity Research Journal, 16(1), 141-148. doi:10.1207/s15326934crj1601_13

Sio, U. N. (2010). The mechanisms underlying incubation in problem solving (Doctoral dissertation). Lancaster University, Lancaster, UK. Retrieved from http://www.psy.cmu.edu/ unsio/PhD_thesis_Sio_incubation.docx

Sio, U. N., \& Ormerod, T. C. (2009). Does incubation enhance problem solving? A meta-analytic review. Psychological Bulletin, 135(1), 94-120. doi:10.1037/a0014212

Sio, U. N., \& Rudowicz, E. (2007). The role of an incubation period in creative problem solving. Creativity Research Journal, 19(2\&3), 307-318. doi:10.1080/10400410701397453 
Smith, S. M. (1995). Getting into and out of mental ruts: a theory of fixation, incubation, and insight. In R. J. Sternberg \& J. E. Davidson (Eds.), The nature of insight (pp. 121-149). Cambridge, MA: MIT Press.

Smith, S. M. (2011). Incubation. In M. A. Runco \& S. R. Pritzker (Eds.), Encyclopedia of creativity ( $2^{\text {nd }}$ ed., Vol. 1, pp. 653-657). Academic Press. doi:10.1016/B978-0-12-375038-9.00121-7

Smith, S. M., \& Beda, Z. (2020). Old problems in new contexts: The context-dependent fixation hypothesis. Journal of Experimental Psychology: General, 149(1), 192-197. doi:10.1037/ xge0000615

Smith, S. M., \& Blankenship, S. E. (1991). Incubation and the persistence of fixation in problem solving. American Journal of Psychology, 104(1), 61-87. doi:10.2307/1422851

Stoet, G. (2010). PsyToolkit: A software package for programming psychological experiments using Linux. Behavior Research Methods, 42(4), 1096-1104. doi:10.3758/BRM.42.4.1096

Stoet, G. (2017). PsyToolkit: A novel Web-based method for running online questionnaires and reaction-time experiments. Teaching of Psychology, 44(1), 24-31. doi:10.1177/0098628316677643

Storm, B. C., \& Patel, T. N. (2014). Forgetting as a consequence and enabler of creative thinking. Journal of Experimental Psychology: Learning, Memory, and Cognition, 40(6), 1594-1609. doi:10.1037/xlm0000006

Strick, M., Dijksterhuis, A., Bos, M. W., \& Nordgren, L. F. (2011). A meta-analysis on unconscious thought effects. Social Cognition, 29(6), 738-762. doi:10.1521/soco.2011.29.6.738

Valueva, E. A. (2016). The role of incubation period in problem solving. Psychology. Journal of Higher School of Economics, 13(4), 789-800. (in Russian)

Vul, E., \& Pashler, H. (2007). Incubation benefits only after people have been misdirected. Memory and Cognition, 35(4), 701-710. doi:10.3758/BF03193308

Wallas, G. (1926). The art of thought. New York: Harcourt Brace Jovanovich.

Yoon, S. Y. (2011, a). Psychometric properties of the Revised Purdue Spatial Visualization Tests: Visualization of Rotations (The Revised PSVT:R) (Ph.D. dissertation). Retrieved from ProQuest Dissertations and Theses. (Order Number: 3480934).

Yoon, S. Y. (2011, b). Revised Purdue Spatial Visualization Test: Visualization of Rotations (Revised PSVT:R) [Psychometric Instrument]. Texas A\&M University, College Station, TX.

Zhong, C.-B., Dijksterhuis, A., \& Galinsky, A. D. (2008). The merits of unconscious thought in creativity. Psychological Science, 19(9), 912-918. doi:10.1111/j.1467-9280.2008.02176.x

Ekaterina A. Valueva - Research Fellow, Institute of Psychology, Russian Academy of Sciences, Ph.D.

Research area: cognitive psychology, intelligence, creativity.

E-mail: ekval@list.ru

Nadezhda M. Lapteva - Junior Research Fellow, Institute of Psychology, Russian Academy of Sciences.

Research area: creativity, cognitive psychology, psychophysiology, embodied cognition.

E-mail: n.m.lapteva@mail.ru 


\title{
Нужно ли забыть фиксации для успешной инкубации? Парадокс теории забывания фиксаций
}

\author{
Е.А. Валуева ${ }^{\text {a }}$ Н.М. Лаптева \\ ${ }^{a}$ ФГБУН «Институт психологии РАН», 129366, Москва, ул. Ярославскал, д. 13, к. 1
}

\section{Резюме}

Целью настоящей работы являлось изучение когнитивных механизмов инкубационного периода, который исследователи рассматривают как важный этап в решении творческих задач. Гипотеза забывания фиксаций - одна из наиболее влиятельных гипотез, претендующих на объяснение успешных случаев инкубации. Эта гипотеза предполагает, что инкубация помогает решателю избавиться от неверных решений и, благодаря этому, приблизиться к верному. В двух исследованиях проверялось предположение этой теории о том, что решатель преодолевает неверные идеи благодаря забыванию фиксаций. В Исследовании 1 применялся тест Необычное использование, при этом часть испытуемых была фиксирована на наиболее распространенных способах использования предмета. Результаты Исследования 1, во-первых, продемонстрировали наличие эффекта инкубации (повышение беглости на второй попытке) только в группе с предварительной фиксацией. Во-вторых, было обнаружено, что инкубация не влияла на число решений теста на альтернативное использование, соответствующих фиксациям. В Исследовании 2 мы использовали анаграммы с двумя возможными решениями и фиксировали участников на одном из них. Затем с помощью задачи лексического выбора проверялось, будут ли следы этих фиксаций становиться слабее в результате инкубационного периода. Результаты выполнения задачи лексического решения свидетельствуют об отсутствии различий во времени реакции на решения-фиксации между группой с инкубацией и без инкубации. В целом наши результаты подтверждают, что инкубационный период помогает преодолеть приверженность неверным идеям, но стоящий за этим механизм не является забыванием фиксаций. Обсуждаются другие возможные механизмы.

Ключевые слова: инкубация, фиксация, гипотеза забывания фиксаций, тест Необычное использование, анаграммы, задача лексического выбора.

Валуева Екатерина Александровна - научный сотрудник, ФГБУН «Институт психологии Российской академии наук», кандидат психологических наук.

Сфера научных интересов: когнитивная психология, интеллект, творчество.

Контакты: ekval@list.ru

Лаптева Надежда Михайловна - младший научный сотрудник, ФГБУН «Институт психологии Российской академии наук».

Сфера научных интересов: креативность, когнитивная психология, психофизиология, воплощенное познание.

Контакты: n.m.lapteva@mail.ru 